\title{
Service and Testing Personnel
}

National Cancer Institute

\section{Source}

National Cancer Institute. Service and Testing Personnel. NCI Thesaurus. Code C53441.

Qualified professionals trained and assigned to conduct the device or equipment maintenance and testing. 